\title{
CHARACTERIZATION OF GAMMA-GLUTAMYL TRANSPEPTIDASE AND UREASE OF Paracoccidioides brasiliensis DURING NITROGEN STARVATION
}

SILVA, L. O. S.; CRUZ-LEITE, V. R. M.; SUDÁRIO, L. D. C.; TOMAZETT, M. V.; PARENTE-ROCHA; J. A.; PACCEZ, J. D.; SOARES, C. M. A.; BORGES, C. L.

Laboratory of Molecular Biology, Institute of Biological Sciences, UFG, Goiânia-GO, Brazil. Email: lanaohara.loss@gmail.com

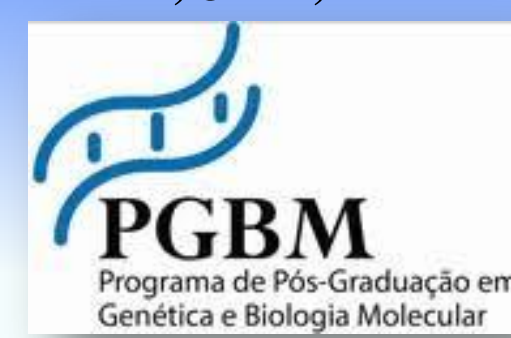

INTRODUCTION

Nitrogen participates in the synthesis of proteins, nucleic acids and others biomolecules, and its uptake and metabolism are essencial to growth and fungal establishment in host milieu (HUERGO et al, 2006; BOLTON, THOMMA, 2008). In this regard, this study aims to evaluate the role of nitrogen in Paracoccidioides brasiliensis (Pb18) pathogenesis, a human pathogenic fungi, through characterization of two proteins, gamma glutamil transpeptidase and urease, that are related to nitrogen metabolism regulation in pathogenic fungi. To reach this objective we expressed the proteins in Escherichia coli heterologous system and started gene silencing through antisense RNA technology.

\section{MATERIALS AND METHODS}

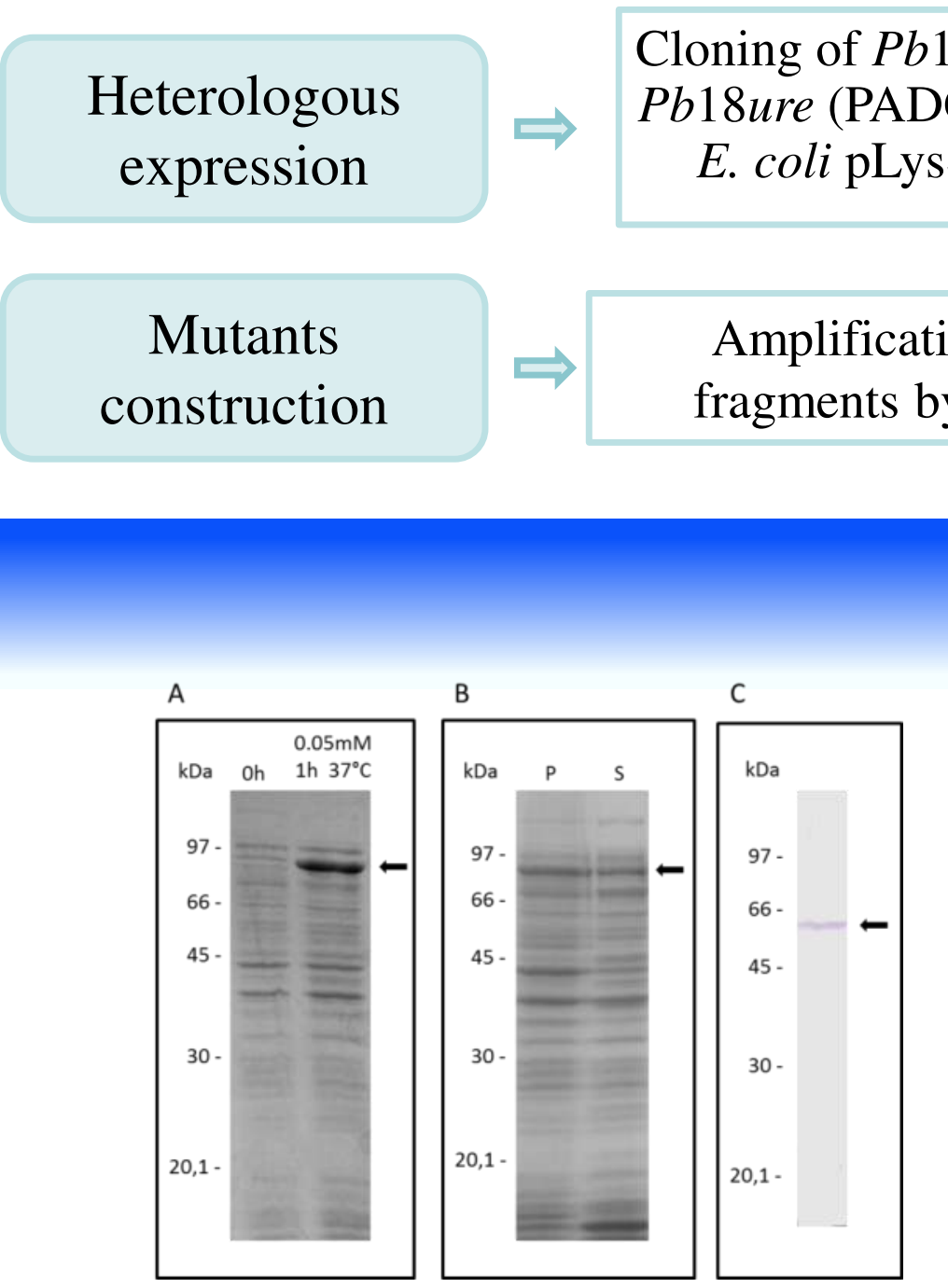

FIGURE 1: Representative figure of $\mathrm{r} P b 18 \mathrm{Ggt}$ and policlonal antiboby $\alpha$-Ggt. A. Induction of rPb18Ggt. (arrow) B. Solubilization of rPb18Ggt (arrow). P: Pellet. S: Supernadant. C. Western-blot of policlonal antiboby $\alpha$-Ggt with Pb01 secretome.

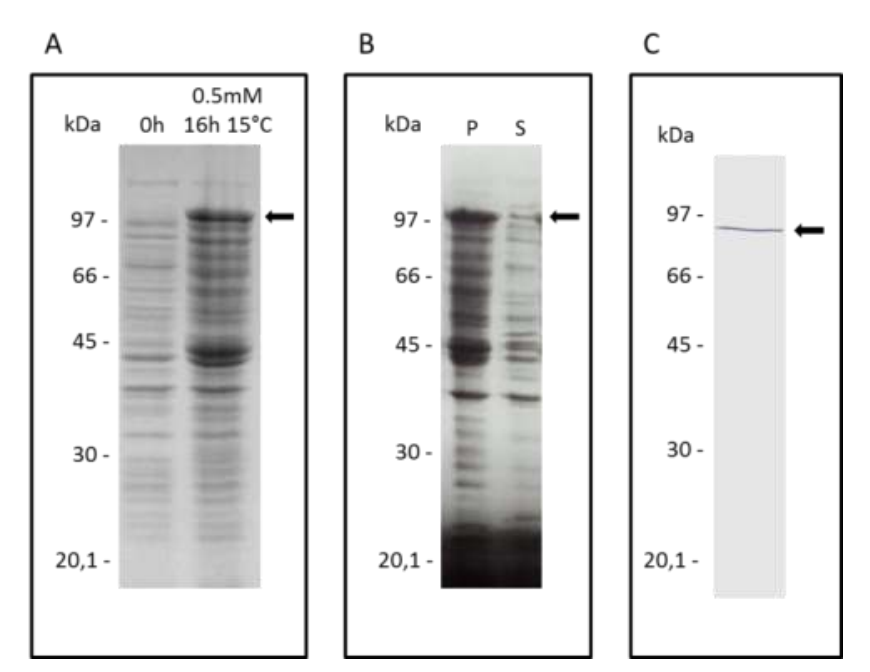

FIGURE 4: Representative image of $\mathrm{r} P b 18 \mathrm{Ure}$ and policlonal antiboby $\alpha$-Ure. A. Induction of rPb18Ure (arrow). B. Solubilization of rPb18Ure (arrow). P: Pellet. S: Supernadant. C. Western-blot of policlonal antiboby $\alpha$-Ure with $P b 01$ citplasmatic proteome.
Induction of $P b 18 \mathrm{Ure}$ and $P b 18 \mathrm{Ggt}$ with IPTG and identification by Nano UPLC-MSE.
Enzymatic activity performing, policlonal antibody production and Western-blot with pUR5750-ggt-aRNA

\section{RESULTS}

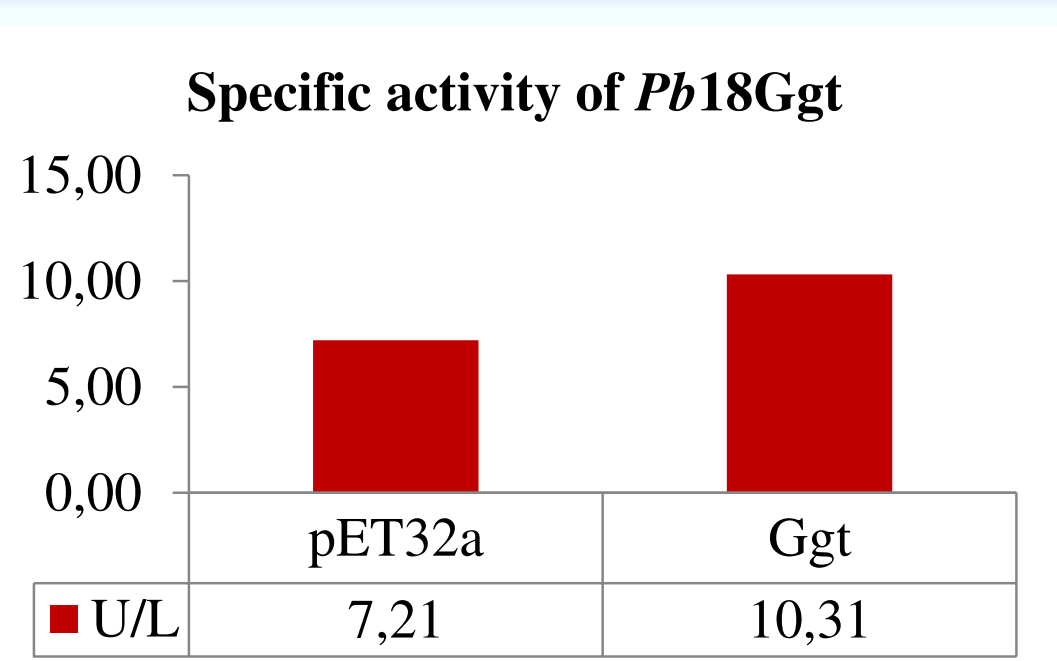

FIGURE 2: Analysis of Pb18Ggt recombinant protein enzimatic activity. pET32a: Enzimatic activity in $\mu \mathrm{mol} / \mathrm{mg} / \mathrm{min}$ of gamma-GT in pET32a induction. Ggt: Enzimatic activity in $\mu \mathrm{mol} / \mathrm{mg} / \mathrm{min}$ of gamma-GT in Pb18Ure induction.

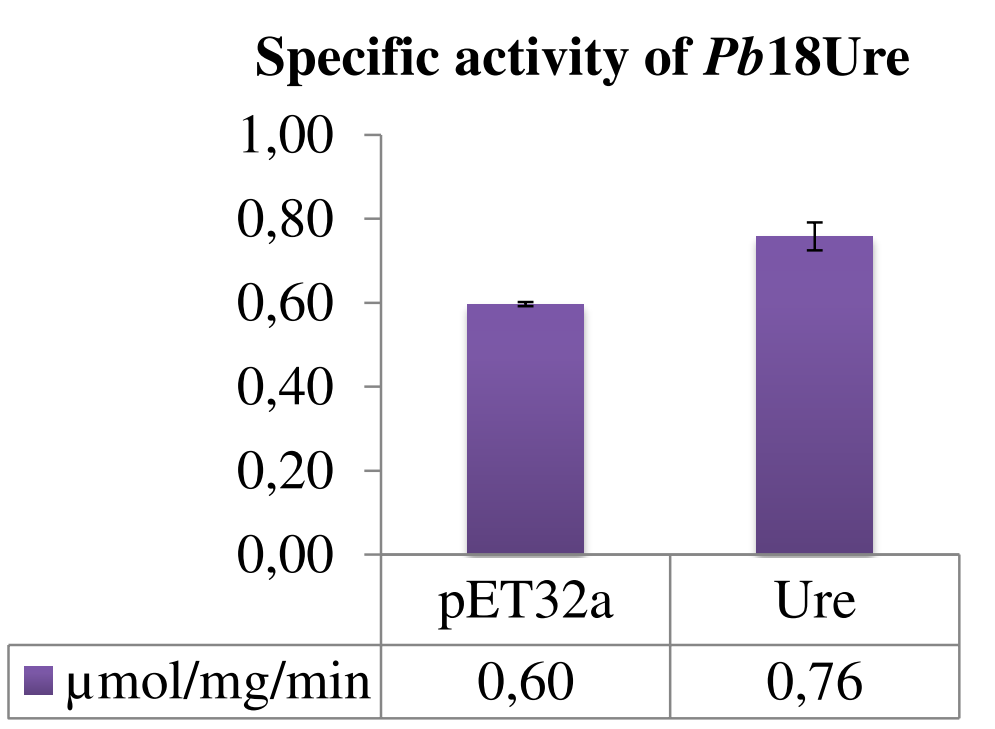

FIGURE 5: Analysis of Pb18Ure recombinant protein enzimatic activity. pET32a: Enzimatic activity in $\mu \mathrm{mol} / \mathrm{mg} / \mathrm{min}$ of Urease in pET32a induction. Ure: Enzimatic activity in $\mu \mathrm{mol} / \mathrm{mg} / \mathrm{min}$ of Urease in $P b 18$ Ure induction. Error bar represents SD of biologic duplicate.

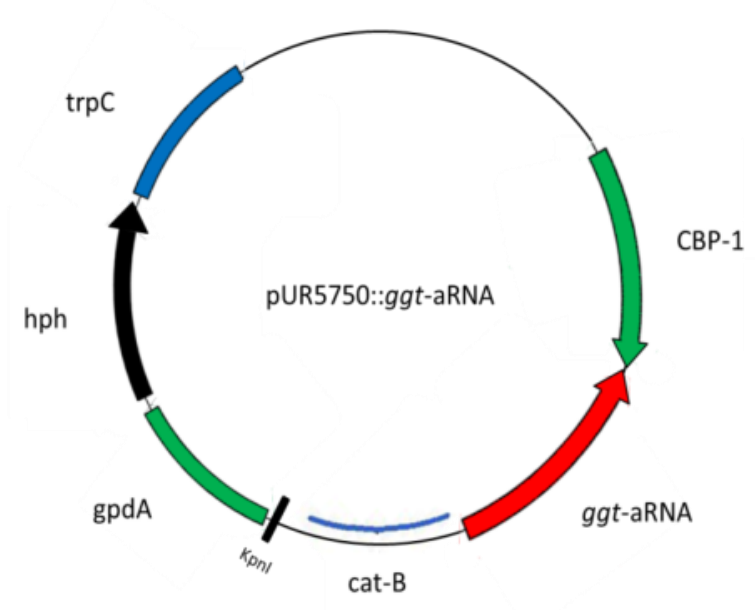

FIGURE 3: pUR5750::Pbggt-aRNA. Antisense ggt cloned in the binary plasmid pUR5750. Red: Antisense ggt. Green: Promoters CBP-1 and gpdA. Blue: Terminator cat-B and trpC. Black: Resistence gene to Hygromycin (hph). KpnI restriction site.

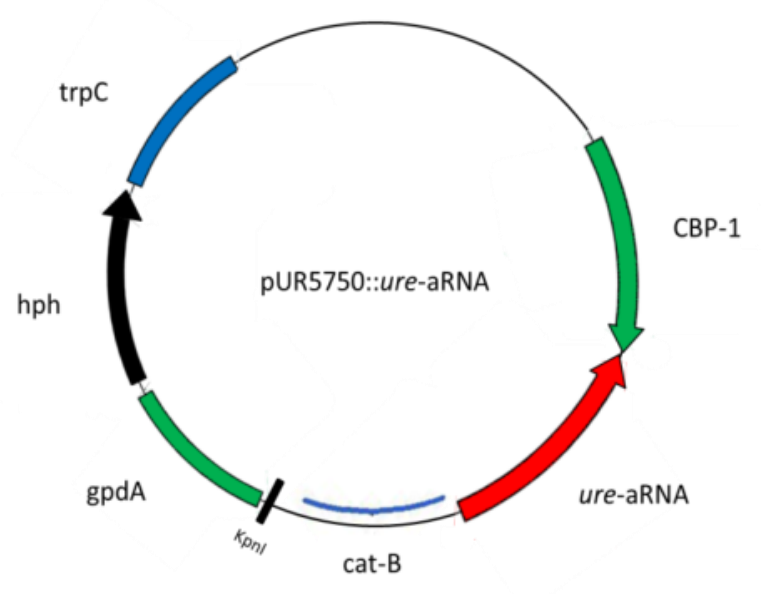

FIGURE 6: pUR5750::Pbure-aRNA. Antisense ure cloned in the binary plasmid pUR5750. Red: Antisense ure. Green: Promoters CBP-1 and gpdA. Blue: Terminator cat-B and trpC. Black: Resistence gene to Hygromycin (hph). KpnI restriction site.

\section{CONCLUSION}

* The proteins gamma-glutamiltranspeptidade and urease were successfully expressed in bacterial heterologous system and demonstrated to be biologically active.

* Still is necessary more studies to ensure if these targets are involved in the uptake of secondary sources of nitrogen in $P b 18$ during nitrogen starvation.

* As a perspective, it is intended to purify the recombinant proteins, and cellular location assays. As well as mice infection and growth on different nitrogen sources of the mutants, in order to inscrease to the data obtained in this work. 